\title{
In vitro and in vivo anti dermatophytes activity of Lawsonia inermis L. (henna) leaves against ringworm and its etiological agents
}

\author{
Nasir Hassan Wagini ${ }^{1, ~ *}$, Mohamed Said Abbas ${ }^{2}$, Amira Shawky Soliman ${ }^{2}$, Yasser Adel Hanafy ${ }^{3}$, \\ El-Saady Mohamed Badawy ${ }^{4}$ \\ ${ }^{1}$ Department of Biology, Faculty of Natural and Applied Sciences, Umaru Musa Yar'adua University, Katsina, Nigeria \\ ${ }^{2}$ Department of Natural Resources, Institute of African Research and Studies, Cairo University, Cairo, Egypt \\ ${ }^{3}$ Medical and Aromatic Plants Unit, Desert Research Center, Cairo, Egypt \\ ${ }^{4}$ Medicinal and Ornamental Plant, Faculty of Agriculture, Cairo University, Cairo, Egypt

\section{Email address:} \\ nhwagini@yahoo.com (N. H. Wagini), msaelsarawy@yahoo.com (M. S. Abbas), sitamira2000@yahoo.com (A. S. Soliman), \\ yasser123oka@yahoo.com (Y. A. Hanafy), saady.badawy@ymail.com (M. E. Badawy)
}

\section{To cite this article:}

Nasir Hassan Wagini, Mohamed Said Abbas, Amira Shawky Soliman, Yasser Adel Hanafy, El-Saady Mohamed Badawy. In Vitro and in Vivo Anti Dermatophytes Activity of Lawsonia Inermis L. (Henna) Leaves against Ringworm and Its Etiological Agents. American Journal of Clinical and Experimental Medicine. Vol. 2, No. 3, 2014, pp. 51-58. doi: 10.11648/j.ajcem.20140203.13

\begin{abstract}
The study was carried out to identify the etiological agents causing ringworm, evaluate the in vitro and in vivo antifungal activity of Lawsonia inermis L. In vitro study was carried out using agar dilution method. In a total of 50 clinical samples, 4 different species were identified namely; Microsporum canis, Trichophyton tonsurans, Trichophyton rubrum, and Trichophyton mentagrophytes. However, the results showed that hexane extract exerted a strong antifungal activity against all the identified etiological agents, with a minimum inhibitory concentration of $625 \mu \mathrm{g} / \mathrm{ml}$ except Microsporum canis which resisted the minimum concentration but susceptible to the higher concentrations. The in vivo study was carried out using 15 naturally infected goats. First, second and third group of animals were treated with henna paste, aqueous and ethanolic extract respectively, fourth group were treated with clotrimazole as a positive control while negative control (fifth) group were left untreated with neither henna nor clotrimazole. The treatments were compared and the results showed that henna paste had the highest efficacy against all the types of ringworm tested compared to the remaining treatments. Disappearance of lesion and complete repair of the hair was observed at 30 days after treatment. Significantly similar result was observed in the group of animals treated with aqueous extract, ethanol extract, and clotrimazole in all the parameters. Significant different was only observed between groups treated and negative control.
\end{abstract}

Keywords: Lawsonia Inermis, Antifungal, Trichophyton, Microsporum, Clotrimazole

\section{Introduction}

Henna (Lawsonia inermis L.) (Lythraceae) is a tall flowering shrub or tree about $5 \mathrm{~m}$ in height, native to tropical and subtropical regions of Africa, southern Asia, and northern Australia in semi-arid zone and oases in the Sahara [1]. Several researchers like [2] have reported the different biological actions of $L$. inermis in various in-vitro and in-vivo test models. Henna leaves, flowers, seeds, stem bark, roots have been found to exhibit antioxidant, antidiabetic, hepatoprotective, hypoglycemic, antimicrobial, anticancer and wound healing properties [3].Traditional medicinal practice has been known for centuries in many parts of the world for the treatment of various human ailments [2]. However, medicinal plants are part and parcel of human society to combat from the dawn of civilization. According to the report of World Health Organization (WHO) $80 \%$ of the world population depend mainly on traditional therapies which involve the use of plant extracts or their active substances [4].

Human and animals infections, especially those associated with skin and mucosal surface constitute a serious problem, especially in tropical and subtropical developing countries [5]. Ringworm is a common contagious disease caused by 
fungi known as dermatophytes, which belong to a group of organisms that are able to break down the keratin in tissues such as the epidermis, hair, nails, feathers, horns and hooves [6]. Most of these fungi reside in the soil and are involved in decomposition; however, the dermatophytes can infect living hosts. Some dermatophytes (anthropophilic species) are adapted to humans, and are usually transmitted from person to person. Others (zoophilic species) are adapted to animals. A few (geophilic) species normally live in the environment, but occasionally act as parasites [7].

Therefore, the aim of this research is to evaluate the in vitro and in vivo antifungal activity of L. inermis.

\section{Materials and Methods}

\subsection{Collection Identification and Preparation of Plant Material}

Henna plant was collected from Wagini town $60 \mathrm{~km}$ east of Katsina in Batsari Local Government Area, Nigeria and transported to the Department of Biology, Umaru Musa Yar'adua University (UMYU) where it was identified as Lawsonia inermis, L. using available information in the laboratory.

\subsection{Extraction and Isolation of Henna}

$100 \mathrm{~g}$ each of the henna powdered was suspended in to $500 \mathrm{ml}$ of ethanol, and extracted using soxhlet extractor for 4 hours [8]. The dried extract were weighed and kept in a freezer until required for further analysis [9].

\subsection{Microorganisms}

50 samples from skin scrapping, hooves and hair were collected from clinically suspected cases of dermatophytosis. The method of samples collection was that prescribed by [6], [10] and [2].

\subsubsection{Microscopic Observation}

A drop of $20 \% \mathrm{KOH}$ (in case of skin and hair) and $40 \%$ (in case of hooves clipping) was kept on a clean, grease free glass slide. Then the sample (Skin scrap and hair) was mixed gently with the $\mathrm{KOH}$ drop and the slide passed through a burner flame to hasten keratolysis (keratolysis softened the sample). This preparation was covered by a clean glass cover slip without trapping any air bubbles. After that the mount was observed under high power objective. In case of nail sample, the nail clippings in $\mathrm{KOH}$ were kept for overnight. Then the mount was observed under high power objective [10].

\subsubsection{Primary Culture of the Samples}

The technique followed by [6] was imitated. Samples collected were inoculated in a dermatophyte test media (DTM) specially prepared for the culture of ringworm (40.7 g of the medium was suspended in one liter of purified water, heated with frequent agitation and boiled for one minute to completely dissolve the medium. autoclaved at $121^{\circ} \mathrm{C}$ for 15 minutes, and cooled to $50^{\circ} \mathrm{C}$. The two antibiotics Gentamicin $(0.1 \mathrm{~g} / \mathrm{L})$ and Chlortetracycline $(0.1 \mathrm{~g} / \mathrm{L})$ were also added to prevent the unwanted growth of bacterial contaminants). The plates were incubated for 7 days and growth was noted and recorded. Another plate was left un-inoculated as control and this was considered as primary culture. The portions of the colonies were subjected to microscopic examination.

\subsubsection{Lacto-Phenol Cotton Blue Mount}

A drop of lacto-phenol cotton blue was placed on the clean grease free glass slide, and a tuff of fungal filament was picked up from the culture plate using teasing needle. Then the filaments were transferred to the lacto phenol stain and gently teased and a clean cover glass was carefully placed over the preparation without any air bubbles. This preparation was examined under high power objective. The hyphae, spore structure and their arrangement were observed [3].

\subsection{Preparation of Pure Culture of the Fungal Isolates}

A pure culture of Microsporum canis, Trichophyton tonsurans, Trichophyton rubrum, and Trichophyton mentagrophytes were prepared by careful subculture of the portion from the primary culture to center of the surface of fresh DTM plates, slants and incubated at room temperature [11].

\subsection{Preparation of Inoculums}

A sterile wire loop was used to transfer a portion of the colony of each isolate onto Triphton Soy Yeast broth (T.S.B) that is incubated at room temperature overnight. $0.1 \mathrm{ml}$ of the overnight broth culture is diluted with $1 \mathrm{ml}$ of the distilled water in a ratio of 1: 100 to form the standard inoculums [6].

\subsection{In Vitro Sensitivity Test by Broth Dilution Method}

\subsubsection{Preparation of Test Plant Extract}

To prepare ethanol soluble fractions of the plant, $100 \mathrm{mg}$ of the extract was dissolved in $1 \mathrm{ml}$ of dimethyl sulfoxide $\left(\mathrm{DMSO}_{4}\right)$ to make a concentration of $100 \mathrm{mg} / \mathrm{ml}$ referred to as solution (a). $0.5 \mathrm{ml}$ of solution (a) was further dissolved in $0.5 \mathrm{ml} \mathrm{DMSO}_{4}$ making solution (b) from which from which $0.5 \mathrm{ml}$ was dissolved in another $0.5 \mathrm{ml} \mathrm{DMSO}_{4}$ to make solution (c). By dissolving $0.5 \mathrm{ml}$ standard solution (c) into $0.5 \mathrm{ml} \mathrm{DMSO}_{4}$, solution (d) was obtained. Therefore, the concentrations of standard solutions b, c and d were 50, 25 and $12.5 \mathrm{mg} / \mathrm{ml}$ respectively.

However, by incorporating $1.0 \mathrm{ml}$ of solution $\mathrm{b}$, c and $\mathrm{d}$ into $9.0 \mathrm{ml}$ of Sabourrauds agar, a final concentrations of $5000,2500,1250$ and $625 \mu \mathrm{g} / \mathrm{ml}$ of the media containing the test extract was obtained respectively.

\subsubsection{Bioassay Procedure}

Sabouraud dextrose agar (SDA) containing $5000 \mu \mathrm{g} / \mathrm{ml}$, $2500 \mu \mathrm{g} / \mathrm{ml}$, and $1250 \mu \mathrm{g} / \mathrm{ml}, 625 \mu \mathrm{g} / \mathrm{ml}$ and clotrimazole were prepared. This prepared SDA of various concentrations of the extract, clotrimazole and another media with no extract 
neither clotrimazole were inoculated with each of the etiological agent and incubated in triplicates at room temperature for 48 hours. Incubation continued up to the next thirty days. Control plates containing no extracts were also inoculated and incubated in each case. Presence or absence of fungal hyphae on the plate at the end of the incubation period were examined and recorded as active $(+)$ when the extracts inhibited a single colony to grow out, otherwise, not active (-) was recorded [11].

\subsection{In-Vivo Sensitivity Testing Using Goats}

Fifteen goats, naturally infected by ringworm of between 10 to 12 months old were identified and obtained from market. They were randomly distributed into 5 groups, with 3 goats in each group. Before conducting the research, the ethical approval of the use of animal was obtained from the National Union of Medical Herbal Practitioners, Nigeria. During the research animals were caged separately in the same yard and supplied with food and water. The experimental protocol following the ethical guidelines on the proper care and use of animals was maintained and adapted throughout the research. The method followed by Al Hamdani et al., [12] was imitated.

Henna paste was prepared by soaking $100 \mathrm{~g}$ of powdered plant in $900 \mathrm{~mL}$ of water [13]. The mixture was stirred until it had a thick, pasty texture. The first group of animal was treated with the paste at the lesions twice daily as prescribed by [14] and [2]. The second group of animals was treated with the aqueous extract. $10 \mathrm{~s} 0 \mathrm{~g}$ each of the powdered leaves was suspended in to $900 \mathrm{ml}$ distilled water and extracted using soxhlet extractor for 4 hours. The extract was filtered using a Whatman's No. 1 filter paper and the filtrate was dried using water bath. Concentration of $5000 \mu \mathrm{g} / \mathrm{ml}$ of the dried extract was prepared using distilled water as solvent and applied topically on the lesions of the second group of animals twice daily. To the third group of animals the same extraction procedure as in previous was repeated but in this case ethanol was used as an extraction solvent in place of distilled water. Clotrimazole cream was obtained from pharmacy and applied topically twice daily on the lesions of the fourth group of animal as prescribed by the manufacturer and this was referred as a positive control. Clotrimazole is used to treat fungal infections of the skin. Plant paste was applied topically on the ringworm lesion created on artificially infected rabbit to evaluate it [12]. [10] Prescribed the topical treatment of the whole-body or individual lesions with clotrimazole or miconazole preparations as one of the best way of treating ringworm. The fifth group of animals was left untreated and considered as a negative control. The samples were collected from the treated lesions and diagnosed for the visibility and observation of viability of the etiological agents at two days interval from the first day of treatment until no viable sample was viewed or obtained. Finally, initial and complete hair regrowth was measured using ruler and the result was recorded. The same process of diagnosis of the lesions was repeated to all other remaining group of animals.

\section{Results and Discussion}

\subsection{Isolation and Identification of Dermophytes}

In this study, a total of 50 clinical samples (skin, hair and hooves) were collected from a total of 23 goats and all the collected samples were plated on dermatophytes test medium (DTM). Most of the dermatophytic fungi were isolated from skin samples than hair and hooves. Based on the colony morphology and microscopic observations, 4 different species were identified and presented in Table (1). They are; Microsporum canis invaded hairs show an ectothrix infection and fluoresce a bright greenish-yellow under Wood's ultra-violet light. Colonies are flat, spreading, white to cream-coloured, with a dense cottony surface and usually have a bright golden yellow to brownish yellow reverse pigment, but non-pigmented strains may also occur. Macroconidia are typically spindle-shaped with 5-15 cells, verrucose, thickwalled and often have a terminal knob. Trichophyton mentagrophytes, colonies that appeared flat, white to cream color with powdery granular, under microscope, a numerous subspherical to pyriform micro conidia, spiral hyphae and spherical chlamydoconidia confirmed to be T. mentagrophytes. Trichophyton rubrum, Flat to slightly raised velvet, yellow brown to red pigment on reverse side of the medium and tear-drop macro conidia, abundant micro conidia as small pyriform observed under microscope and T. tonsurans appear suede-like to powdery, flat with a raised center or folded, often with radial grooves, hyphae are relatively broad, irregular, much branched with numerous septa and numerous characteristic microconidia varying in size and shape from long clavate to broad pyriform, are borne at right angles to the hyphae, which often remain unstained by lactophenol cotton blue. Shahitha et al., [3] reported that a total of 6 species of dermatophytes viz., Trichophyton rubrum, Trichophyton verrucosum, Trichophyton tonsurans, Trichophyton equinum, Microsporum canis and Microsporum gypsum were isolated and identified from 50 samples collected from clinically suspected cases of dermatophytosis.

Table 1. Growth screening of ringworms species on the Dermatophyte Test Medium (DTM).

\begin{tabular}{|c|c|c|c|c|}
\hline Ringworm & M. canis & T.mentagrophytes & T. rubrum & T. tonsurans \\
\hline scalp & + & + & + & + \\
\hline face & + & - & + & - \\
\hline body & + & + & + & - \\
\hline
\end{tabular}

\subsection{In Vitro Antidermatophytic Assay}

In this study, anti dermatophytic activity of Lawsonia inermis (henna) against the isolates of Microsporum canis, Trichophyton rubrum, Trichophyton mentagrophytes, and Trichophyton tonsurans, were obtained frequently in all the detected samples. The ethanol extract in Table (2) showed strong antifungal activity against Microsporum canis, $T$. 
mentagrophytes, and T. rubrum at all the concentrations; at concentration of $625 \mu \mathrm{g} / \mathrm{ml}$ and $1250 \mu \mathrm{g} / \mathrm{ml} \mathrm{T}$. tonsurans was found to be resistant to the test plant. This proved that the higher the concentration the better the fungicidal effect. Mansour et al., [16] reported in their research that $L$. inermis leaves extract have developed a fungicidal effect against $T$. mentagrophytes and Candida albicans. Padron-Marquez et al., [5] reported that compared to control, the best antifungal activity found in their investigation was observed with the hexane extract, which inhibited all the tested dermatophytes. [16] Reported in their research that $L$. inermis leaves extract have developed a fungicidal effect against $T$. mentagrophytes and Candida albicans. Nasreen et al., [15] reported that during screening of barks of 30 plant species against dermatophytes, only Lawsonia inermis (Henna) extract exhibited absolute toxicity. The extract showed broad fungitoxic spectrum when tested against 13 ring worm fungi. Lawsonia inermis exhibited absolute toxicity against ringworm causing fungal species such as Microsporum gypseum and Trichophyton mentagrophytes [1].

Table 2. Sensitivity test of the ethanol L. inermis leaf extract on the growth of individual species of dermatophytes.

\begin{tabular}{lcccc}
\hline & Conc. & Conc. & Conc. & Conc. \\
Dermatophyte species & $\begin{array}{c}\boldsymbol{\mu g} / \mathbf{m l} \\
\mathbf{5 0 0 0}\end{array}$ & $\begin{array}{c}\boldsymbol{\mu g} / \mathbf{m l} \\
\mathbf{2 5 0 0}\end{array}$ & $\begin{array}{c}\boldsymbol{\mu g} / \mathbf{m l} \\
\mathbf{1 2 5 0}\end{array}$ & $\begin{array}{c}\boldsymbol{\mu g} / \mathbf{m l} \\
\mathbf{6 2 5}\end{array}$ \\
\hline Microsporum canis & + & + & + & + \\
T. mentagrophytes & + & + & + & + \\
T. tonsurans & + & + & & - \\
T. rubrum & + & + & + & + \\
\hline
\end{tabular}

Key $+=$ sensitive $-=$ not sensitive

\subsection{In Vivo Antidermatophytic Assay}

Hair resume growing after the microorganism became susceptible to the treatments and initial regrowth was noticed and recorded in Table (3), per Days After Treatment (DAT). However, hair regrowth was fist noticed at 5DAT in groups of henna paste, ethanol extract, and clotrimazole cream, while respectably 6DAT and 39DAT in aqueous extract and negative control groups. Likewise, the sample of etiological agents collected from the treated region of infection was only viable at 3DAT, but the progress of inhibition of the growth and development of the dermatophytes was noticed at 4 days after treatment in which no visible growth of fungal was seen from the cultured samples. Regrowth of hair in the treated lesions was first noticed at 13 days after treatment. Subsequently, disappearance of lesion and complete regrowth of the hair was observed at 30 days after treatment. Figure (1, 2, 3 and 4) shows image of the lesions of the ringworm before and after treatment with henna paste, ethanolic extract, aqueous extract and clotrimazole cream respectively, while figure (5) shows the image of one of the control animal at the beginning of treatment and at the time where all the treated groups completely recovered. Significantly similar result was observed in the group of animals treated with aqueous extract, ethanol extract, and clotrimazole in all the parameters. Significant different was observed between groups treated with all the previously listed extracts, clotrimazole (positive control) and Control (negative control) in each case. Lawsone, 2-hydroxy-1,4-naphthoquinone was considered by [17] to be responsible for henna's fungicidal activity. The result of [22] in 2014 supports the traditional usage of the L. inermis and suggests that the henna extracts possess compounds used in traditional medicine. While the findings of [8] demonstrated that henna extracts have antifungal activity in vitro against the fungal which causes Pityriasis versicolor, Pityrosporum foliculities and dandruff. They added that aqueous extracts are more effective on Malassezia than methanolic and chloroformic extracts. However, in most cases, the biological activity of henna against ringworm and its etiological agents is related to the ability of quinones to accept one or two electrons from microorganisms to form highly reactive radical anion intermediates, which are responsible for the oxidative stress observed in the microbial cells [18]. In fact, some clinically active antimicrobial drugs, such as marinone debromomarinone, contain the quinone moiety as a relevant part of their structures [19]. Quinonoid compounds by virtue of their easy redox cycling capacity are known to possess wide-ranging antimicrobial as well as anti-cancer features. Therefore Lawsone, 2-hydroxy-1, 4-naphthoquinone is responsible for henna's fungicidal activity [17].

Table 3. Comparative Anti fungal susceptibility testing of ringworm infected goats treated with the henna paste, aqueous extract, ethanolic extract, clotrimazole and control.

\begin{tabular}{|c|c|c|c|c|c|c|}
\hline \multirow{2}{*}{ Treatment type } & \multicolumn{5}{|c|}{ Response of treatments/days } & \multirow{2}{*}{$\begin{array}{l}\text { LSD } \\
0.05\end{array}$} \\
\hline & Improvement & Negative culture of hair & Initial re growth of hair & Disappearance of lesions & Total & \\
\hline Henna paste & 5 & 4 & 13 & 30 & 39 & 4.03 \\
\hline Aqueous extract & 6 & 4 & 13 & 30 & 40 & 4.03 \\
\hline Ethanol extract & 5 & 5 & 11 & 30 & 40 & 4.03 \\
\hline Clotrimazole cream & 5 & 4 & 13 & 27 & 36 & 3.99 \\
\hline Control & 39 & 48 & 44 & 70 & 157 & 8.33 \\
\hline
\end{tabular}




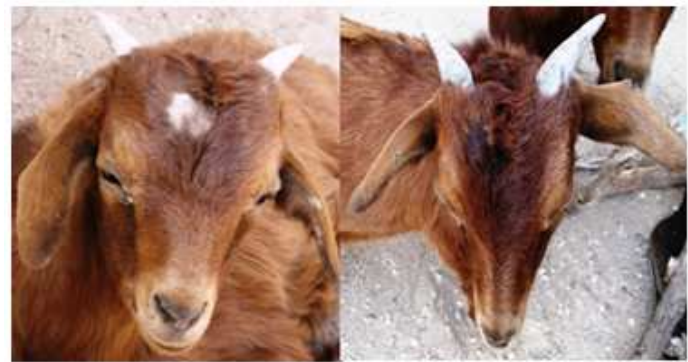

(a)

(b)

Figure 1. Before and after the In vivo sensitivity test of henna paste on goat naturally infected by ringworm.

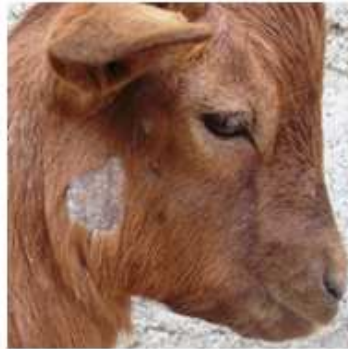

(a)

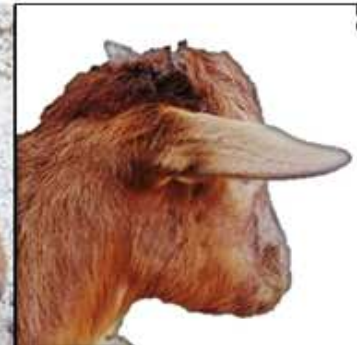

(b)
Figure 2. Before and after the In vivo sensitivity test of Lawsonia inermis ethanolic extract on goat naturally infected by ringworm.

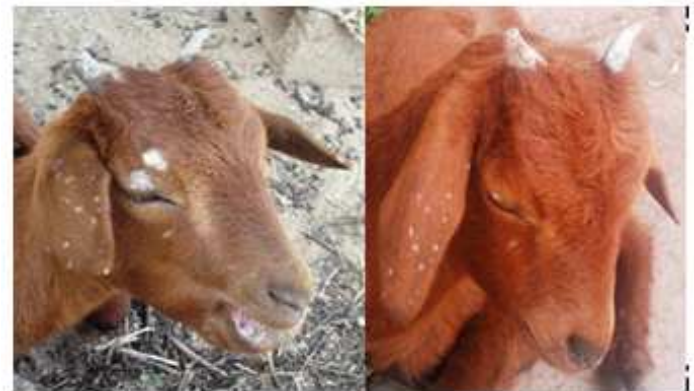

(a)

(b)

Figure 3. Before and after the In vivo sensitivity test of Lawsonia inermis aqueous extract on goat naturally infected by ringworm.

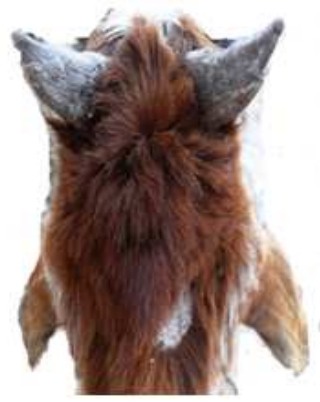

(a)

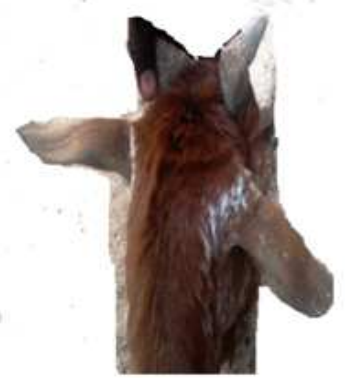

(b)
Figure 4. Before and after the In vivo sensitivity test of Lawsonia inermis clotrimazole on goat naturally infected by ringworm.

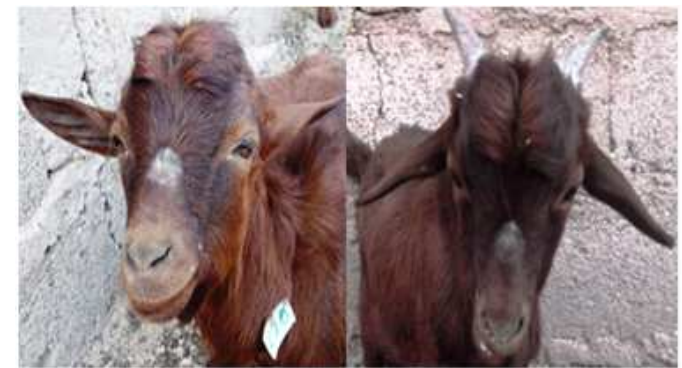

(a)

(b)

Figure 5. The negative control animals which was left untreated before and after the research in which left at the beginning of the research while right at the end of the research.

\subsection{Percentage Cure and Regrowth of Hair}

The percentage hair growth results and graphical representation of both treatments and types of ringworm are given in Tables (4, 5 and 6) and Figure (6,7 and 8). Moreover, measurement of percentage of hair length begin when the hair reaches $5 \%$ of its original length. However, the highest initial percentage (11.50 \pm 1.23$)$ regrowth of hair against ringworm of scalp during treatment was first observed at 15DAT in group treated with clotrimazole cream (positive control, followed by group treated with aqueous extract $(7.50 \pm 1.77)$ and henna paste respectively $(7.40 \pm 1.56)$ and the lowest percentage $(5.32 \pm 1.17)$ was observed in group treated with ethanol extract both at 16DAT. How ever, reasonable initial percentage in control was first observed at 45DAT. The result is summarized in table 4 and Figure (6). Likewise, full hair regrowth to $100 \%$ was initially observed in group treated with clotrimazole cream at 25DAT, followed by groups treated with henna paste, ethanol extract and aqueous extract at 30DAT each. Finally, control reaches its $100 \%$ regrowth at 70 DAT. Consequently, the data presented in Table 3 and Table 6 indicates Percentage regrowth of hair against ringworm of face and ringworm of body respectably during treatment. Hence, initial and $100 \%$ regrowth was observed at 15DAT and 25DAT respectively in group treated with clotrimazaole, while, initial and $100 \%$ regrowth was observed at 15DAT and 30DAT in the remaining treatments and finally initial and $100 \%$ regrowth was observed at 45DAT and 70DAT in controlled groups. However, in animals ringworm infection generally runs a course within a few weeks or months and disappears even without treatment. On contrary, to the ringworm of scalp in children which if not treated remain active on their hosts until they reaches puberty. Therefore, treatment; speed up recovery time, minimizes further spread of the disease to different part of the body or to the available susceptible host and or to the surrounding area. Furthermore, it prevents possible damage such as permanent alopecia on the affected area if allowed to heal on its own. Tinea capitis patient treated with Euphorbia paralias matrix has completely recovered with hair growth after a month of starting the treatment [2]. The findings by Fariba et al. [5] demonstrated that henna 
extracts have antifungal activity in vitro against the fungal which causes Pityriasis versicolor, Pityrosporum foliculities and dandruff. They added that aqueous extracts are more effective on Malassezia than methanolic and chloroformic extracts. Al-ani et al., [20] reported that domestic animals of different ages are susceptible to ringworm infection. Their results showed that rapid and effective cure of affected calves occurred with two to three applications of locally prepared ointment at 3-4-day intervals. However, it was reported that irrespective of sex, the extract-oil formulation extract from the stem bark of Polyscias fulva Hiern (Araliaceae) at 5\% was able to cure ringworm infected animals after fourteen days of treatment while griseofulvin produced the same effect after thirteen days [21].

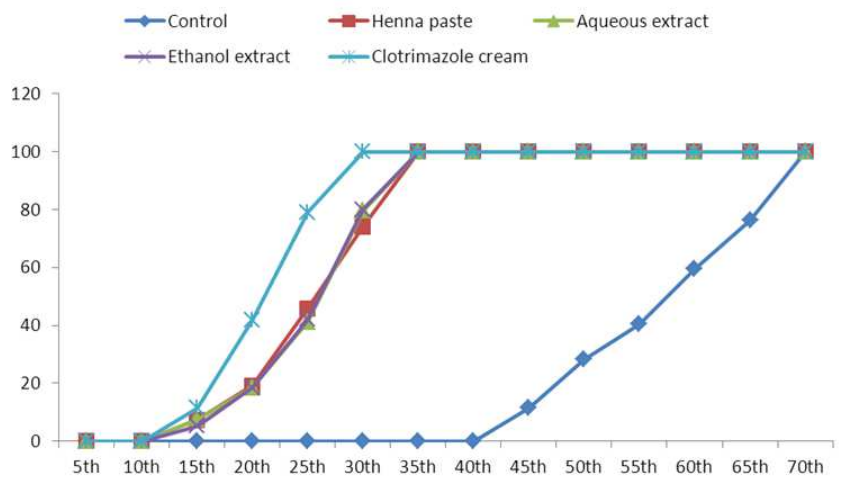

Figure 6. Percentage regrowth of hair in lesions of the ringworm of scalp per days after treatment.

Table 4. Percentage regrowth of hair against ringworm of scalp during treatment.

\begin{tabular}{|c|c|c|c|c|c|}
\hline $\begin{array}{l}\text { Days after } \\
\text { treatment }\end{array}$ & Control & $\begin{array}{c}\text { Henna } \\
\text { paste }\end{array}$ & $\begin{array}{c}\text { Aqueous } \\
\text { extract }\end{array}$ & $\begin{array}{c}\text { Ethanol } \\
\text { extract }\end{array}$ & $\begin{array}{c}\text { Clotrimazo } \\
\text { le cream }\end{array}$ \\
\hline 5 & 0.00 & 0.00 & 0.00 & 0.00 & 0.00 \\
\hline 10 & 0.00 & 0.00 & 0.00 & 0.00 & 0.00 \\
\hline 15 & 0.00 & $\begin{array}{c}7.40 \pm 1.5 \\
6\end{array}$ & $7.50 \pm 1.77$ & $5.32 \pm 1.17$ & $11.50 \pm 1.23$ \\
\hline 20 & 0.00 & $\begin{array}{c}19.33 \pm 1 \\
13\end{array}$ & $\begin{array}{c}18.53 \pm 0.3 \\
6\end{array}$ & $\begin{array}{c}18.57 \pm 0.1 \\
2\end{array}$ & $42.00 \pm 0.74$ \\
\hline 25 & 0.00 & $\begin{array}{c}45.83 \pm 0 \\
35\end{array}$ & $\begin{array}{c}41.33 \pm 0.1 \\
2\end{array}$ & $\begin{array}{c}42.10 \pm 0.7 \\
4\end{array}$ & $79.13 \pm 0.72$ \\
\hline 30 & 0.00 & $\begin{array}{c}74.23 \pm 0 \\
70\end{array}$ & $\begin{array}{c}79.66 \pm 1.2 \\
2\end{array}$ & $\begin{array}{c}80.13 \pm 0.7 \\
2\end{array}$ & 100 \\
\hline 35 & 0.00 & 100 & 100 & 100 & 100 \\
\hline 40 & 0.00 & 100 & 100 & 100 & 100 \\
\hline 45 & $\begin{array}{c}11.57 \pm 1 \\
.04\end{array}$ & 100 & 100 & 100 & 100 \\
\hline 50 & $\begin{array}{c}28.37 \pm 2 \\
.14\end{array}$ & 100 & 100 & 100 & 100 \\
\hline 55 & $\begin{array}{c}40.53 \pm 1 \\
.22\end{array}$ & 100 & 100 & 100 & 100 \\
\hline 60 & $\begin{array}{c}59.57 \pm 1 \\
.16\end{array}$ & 100 & 100 & 100 & 100 \\
\hline 65 & $\begin{array}{c}76.26 \pm 1 \\
.12\end{array}$ & 100 & 100 & 100 & 100 \\
\hline 70 & 100 & 100 & 100 & 100 & 100 \\
\hline
\end{tabular}

Table 5. Percentage regrowth of hair against ringworm of face during treatment.

\begin{tabular}{|c|c|c|c|c|c|}
\hline $\begin{array}{l}\text { Days after } \\
\text { treatment }\end{array}$ & Control & $\begin{array}{c}\text { Henna } \\
\text { paste }\end{array}$ & $\begin{array}{c}\begin{array}{c}\text { Aqueous } \\
\text { extract }\end{array} \\
\end{array}$ & $\begin{array}{c}\text { Ethanol } \\
\text { extract }\end{array}$ & $\begin{array}{c}\text { Clotrimazol } \\
\text { e cream }\end{array}$ \\
\hline 5 & 0.00 & 0.00 & 0.00 & 0.00 & 0.00 \\
\hline 10 & 0.00 & 0.00 & 0.00 & 0.00 & 0.00 \\
\hline 15 & 0.00 & $\begin{array}{c}18.37 \pm 1.1 \\
4\end{array}$ & $\begin{array}{c}13.41 \pm 1.4 \\
6\end{array}$ & $\begin{array}{c}14.42 \pm 1.2 \\
1\end{array}$ & $28.37 \pm 1.24$ \\
\hline 20 & 0.00 & $\begin{array}{c}42.20 \pm 0.6 \\
4\end{array}$ & $\begin{array}{c}21.19 \pm 1.2 \\
3\end{array}$ & $\begin{array}{c}23.17 \pm 1.1 \\
4\end{array}$ & $62.12 \pm 0.84$ \\
\hline 25 & 0.00 & $\begin{array}{c}60.10 \pm 0.7 \\
2\end{array}$ & $\begin{array}{c}42.20 \pm 0.7 \\
4\end{array}$ & $\begin{array}{c}47.60 \pm 0.1 \\
4\end{array}$ & $84.23 \pm 0.32$ \\
\hline 30 & 0.00 & $\begin{array}{c}80.23 \pm 1.1 \\
1\end{array}$ & $\begin{array}{c}77.73 \pm 0.7 \\
2\end{array}$ & $\begin{array}{c}87.73 \pm 0.7 \\
4\end{array}$ & 100 \\
\hline 35 & 0.00 & 100 & 100 & 100 & 100 \\
\hline 40 & 0.00 & 100 & 100 & 100 & 100 \\
\hline 45 & $\begin{array}{c}15.27 \pm 1 \\
33\end{array}$ & 100 & 100 & 100 & 100 \\
\hline 50 & $\begin{array}{c}38.24 \pm 1 \\
17\end{array}$ & 100 & 100 & 100 & 100 \\
\hline 55 & $\begin{array}{c}50.82 \pm 1 \\
25\end{array}$ & 100 & 100 & 100 & 100 \\
\hline 60 & $\begin{array}{c}79.56 \pm 1 \\
90\end{array}$ & 100 & 100 & 100 & 100 \\
\hline 65 & $\begin{array}{c}86.44 \pm 1 \\
75\end{array}$ & 100 & 100 & 100 & 100 \\
\hline 70 & 100 & 100 & 100 & 100 & 100 \\
\hline
\end{tabular}

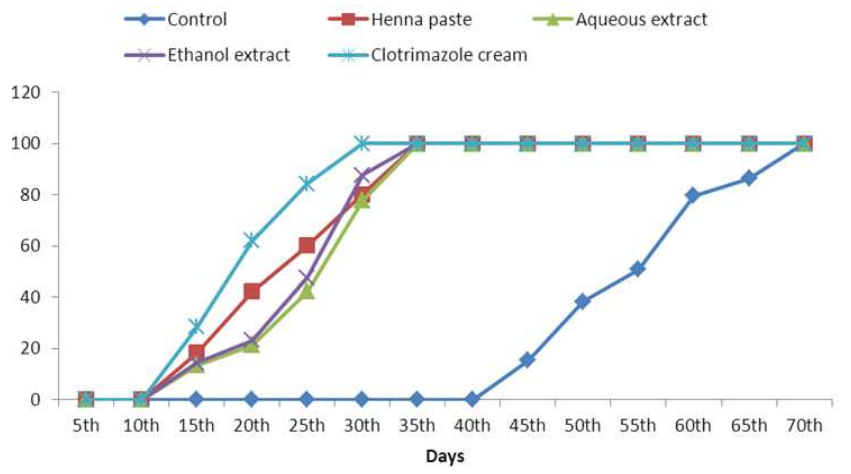

Figure 7. Percentage regrowth of hair in lesions of the ringworm of face per days after treatment.

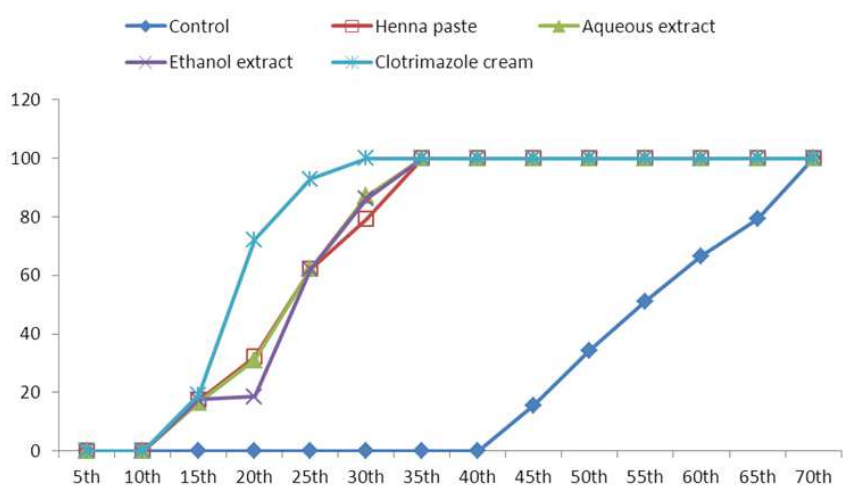

Figure 8. Percentage regrowth of hair in lesions of the ringworm of body per days after treatment. 
Table 6. percentage regrowth of hair against ringworm of body during treatment.

\begin{tabular}{|c|c|c|c|c|c|}
\hline $\begin{array}{l}\text { Days after } \\
\text { treatment }\end{array}$ & Control & $\begin{array}{l}\text { Henna } \\
\text { paste }\end{array}$ & $\begin{array}{c}\text { Aqueous } \\
\text { extract }\end{array}$ & $\begin{array}{c}\text { Ethanol } \\
\text { extract }\end{array}$ & $\begin{array}{c}\text { Clotrimazol } \\
\text { e cream }\end{array}$ \\
\hline 5 & 0.00 & 0.00 & 0.00 & 0.00 & 0.00 \\
\hline 10 & 0.00 & 0.00 & 0.00 & 0.00 & 0.00 \\
\hline 15 & 0.00 & $\begin{array}{c}17.48 \pm 1.2 \\
4\end{array}$ & $\begin{array}{c}16.70 \pm 1.1 \\
6\end{array}$ & $\begin{array}{c}17.58 \pm 1.1 \\
7\end{array}$ & $19.27 \pm 0.12$ \\
\hline 20 & 0.00 & $\begin{array}{c}32.20 \pm 0.3 \\
1\end{array}$ & $\begin{array}{c}31.10 \pm 1.2 \\
3\end{array}$ & $\begin{array}{c}18.67 \pm 1.6 \\
5\end{array}$ & $72.12 \pm 0.55$ \\
\hline 25 & 0.00 & $\begin{array}{c}62.12 \pm 1.1 \\
2\end{array}$ & $\begin{array}{c}62.24 \pm 0.3 \\
4\end{array}$ & $\begin{array}{c}62.10 \pm 0.4 \\
3\end{array}$ & $92.84 \pm 1.12$ \\
\hline 30 & 0.00 & $\begin{array}{c}79.23 \pm 0.1 \\
1\end{array}$ & $\begin{array}{c}87.13 \pm 0.7 \\
2\end{array}$ & $\begin{array}{c}86.13 \pm 0.5 \\
5\end{array}$ & 100 \\
\hline 35 & 0.00 & 100 & 100 & 100 & 100 \\
\hline 40 & 0.00 & 100 & 100 & 100 & 100 \\
\hline 45 & $\begin{array}{c}15.57 \pm 1 \\
.13\end{array}$ & 100 & 100 & 100 & 100 \\
\hline 50 & $\begin{array}{c}34.34 \pm 0 \\
.13\end{array}$ & 100 & 100 & 100 & 100 \\
\hline 55 & $\begin{array}{l}51.12 \pm 1 \\
.15\end{array}$ & 100 & 100 & 100 & 100 \\
\hline 60 & $\begin{array}{c}66.56 \pm 1 \\
.10\end{array}$ & 100 & 100 & 100 & 100 \\
\hline 65 & $\begin{array}{c}79.24 \pm 1 \\
.50\end{array}$ & 100 & 100 & 100 & 100 \\
\hline 70 & 100 & 100 & 100 & 100 & 100 \\
\hline
\end{tabular}

\section{Conclusion}

Base on this research varieties of etiological agents were identified to cause infectious dermatoses among domestic animals in Northern part of Nigeria. The in-vitro and in-vivo sensitivity test of henna provide us with positive antifungal activity against all the etiological agents identified and have the efficacy to cure all the tested animals within a reasonable time. Therefore, the antimicrobial properties of the medicinal plants are reported from all over world and used in the treatment of many diseases such as ringworm and other skin infections. Medicinal plants are the best source to obtain a variety of newer herbal drugs. The result of this study showed that henna paste had the efficacy against all the types of ringworm tested. Therefore, topical application of this natural product (henna) paste is recommended for domestic animals that suffer from all types of ringworms, as it is affordable, available, and highly active and no adverse effect was observed. However, further research to isolate and purify active antifungal agents in henna plant is recommended.

\section{References}

[1] Singh YV, Kumar S and Singh M. Agro History, Uses, Ecology and Distribution of Henna (Lawsonia Inermis). Jodpur, India. Central and Arid-zone Research Institute 2005; 1(1): 11-12.

[2] Mohamed E, Dalia S, Hatem H, Fatma A, Bayoumi E, Aida Abdel and Kader I. A multicenter clinicomycological study evaluating the spectrum of adult Tinea capitis in Egypt. Acta Dermatovenerologica Alpina, Pannonica et Adriatica 2013; (22):77-82.
[3] Shahitha S, Saranya $M$ and Poornima K. Isolation and Identification of Dermatophytes from Clinical Samples and Antidermatophytic Activity of Lawsonia inermis (Henna plant) International Journal of Pharmaceutical and Chemical Sciences 2013; 2(2):1050.

[4] Daljit S, Singh A and Gurinderjeeet K. Antibacterial activity of some India medicinal plants. Journal of Natural Medicine 2007; 2(61):313-317.

[5] Padron-Marquez B, Viveros-Valdez E, Oranday-Cardenas A and Carranza-Rosales P. Antifungal activity of Psidium guajava organic extracts against dermatophytic fungi. Journal of Medicinal Plants Research 2012; 6(41):5435-5438.

[6] Mukhtar MD and Huda M. Prevlence of Tinea capitis in primary school and sensitivity of etiological agents on Pistia stratiotes extracts. Nigerian Journal of Microbilogy 2005; 1(19): 412-415.

[7] Falahati M, Nasim OT And Fereshteh J. Anti Dermatophyte Activities of Eucalyptus camaldulensis in Comparison with Griseofulvin Iranian Journal of Pharmacology \& Therapeutics 2005; 5(42):80-83.

[8] Fariba B, Hassan R and Homeyra E. In vitro study of the effects of henna extracts (Lawsonia inermis) on Malassezia species. Jundishapur Journal of Microbiology 2010; 3(3):125-128

[9] Kawo AH and Kwa AM. Phytochemical screening and antibacterial activity of the aqueous extracts and fractions of ethanolic extracts of Lawsonia inermis Leaf. International Research Journal of Microbiology 2011; 2(12):510-516.

[10] Kahn CM and Line S. The Merck Veterinary Manual. 9th edition. Merck \& Co., Inc. USA. 2005,706.

[11] Baker H. Symptoms and sings in dermatophytical diagnosis. Clinical dermatology, 1st edition, Bailliere Tidal Ltd, London, 1989, 22.

[12] Al-Hamadani AH and Al-Mehna BM. Study the effect of Lawsonia inermis extract on the Trichophyton mentagrophytes in vitro and in vivo Coll. of Vet.Med. University of Medical Sciences. Al-Qadissiya Journl 2009; 1(6);115

[13] Rahmoun, NM, Boucherit-Otmani Z, Boucherit K, Benabdallah, M, Villemin D and Choukchou-Braham B. Antibacterial and antifungal activity of lawsone and novel naphthoquinone derivatives, Med. Mal. Infection 2012; 42(6):270-275.

[14] Adejmo TO. and Bamidele BS. Control of dermatophyte-causing agents using six medicinal plants. Journal of Medicinal Plants Research 2009; 3(11):906-913.

[15] Nasreen K, Hidayatullah A, Abdul Q, Jawed A and Muhammed S. Isolation and identification of dermatophytes from Sindh, Pakistan. Pakistan Journal of Botany 2006; 38(2):493-495.

[16] Mansour-Djaalab H, Kahlouche-Riachi F, Djerrou Z, Serakta-Delmi, M, Hamimed, S, et al. In vitro evaluation of antifungal effects of Lawsonia inermis, Pistacia lentiscus and Juglans regia. International Journal of Medicinal and Aromatic Plants 2012; 2(2): 263-268.

[17] Ahmadian S and Fakhree MA. Henna (Lawsonia inermis) might be used to prevent mycotic infection. Med Hypotheses 2009; (2)73:629-30. 
[18] Valderrama JA, Leiva H, Rodriguez JA, Theoduloz C and Schmeda-Hirshmann G. Studies on quinones Synthesis and cytotoxic evaluation of polyoxyethylenecontaining 1,4-naphthoquinones, Bioorganic and Medicinal Chemistry 2008; 16(7):3687-3693.

[19] Pathirana C, Jensen PR and Fenical W. Marinone and debromomarinone: Antibiotic sesquiterpenoid naphthoquinones of a new structure class from a marine. Scripps Institution of Oceanography 1992; 33(50):7663-7666.

[20] Al-Ani F. K, Younes F. A., Al-Rawashdeh O. F (2002). Ringworm Infection in Cattle and Horses in Jordan . Journal Acta Veterinaria Brno71: 55-60.
[21] Keilah L. Guy Sedar Singor N., Donatien G., R M, P. and Jules-Roger K. In vitro and in vivo antidermatophytic activity of the dichloromethane-methanol $(1: 1 \mathrm{v} / \mathrm{v})$ extract from the stem bark of Polyscias fulva Hiern (Araliaceae). Complementary and Alternative Medicine 2013, 19: 13:95.

[22] Wagini NH, Soliman AS, Abbas MS, Hanafy YA, Badawy EM, Phytochemical Analysis of Nigerian and Egyptian Henna (Lawsonia Inermis L.) Leaves using TLC, FTIR and GCMS, Plant. 2014, 2(3), 27-32. 